Achieving a proper characterization of the pathways involved in endothelin biosynthesis has proved a more difficult goal than we might have predicted, absorbing for more than six years the efforts of a number of resourceful research groups ${ }^{4}$. The precursor of ET-1, big ET-1, may be cleaved from its own precursor by the action of furin at dibasic pairs of amino acids (R. Leduc, Univ. of Sherbrooke, Canada). ET-1 is then freed from big ET-1 by a specific endothelinconverting enzyme(s) (ECE). This latter enzyme has now been cloned and expressed and the molecular structures of a number of related ECEs derived. These have now been named ECE-1a, ECE-1b and ECE-2 and show different preferences for big ET-1, big ET-2 and big ET-3 as substrates (S. Kimura, Chiba Univ., Japan; N. Emoto, Univ. of Texas; O. Valdenaire, Hoffmann LaRoche, Switzerland).

Recent advances in the development of endothelin-receptor antagonists have accelerated the pace of investigations into the true pathophysiological roles of endothelins in mature animals and humans, and now hold out the prospect of the development of new therapeutic drugs. Potent peptide antagonists of the endothelin receptors have been available for the past five years, but these compounds have disadvantages. They are difficult to administer over long periods as they are not orally active, and they are particularly short-lived within the body. But despite their shortcomings, these compounds have been used to establish some interesting facts, such as the role of endothelin in monocrotaline-induced pulmonary hypertension in rats 5 .

Now, however, with the availability of orally active non-peptide antagonists, the active involvement of endogenous endothelins in a variety of pathologies such as myocardial ischaemia/reperfusion (M. Kojima, Takeda Chemical Industries, Japan; J. Pernow, Karolinksa Inst., Stockholm), renal failure (D. P. Brooks, SmithKline Beecham, USA), experimental stroke (T. R. Patel, Univ. of Glasgow) cerebral focal ischaemia (F. C. Barone, SmithKline Beecham, USA), and some forms of systemic hypertension (E. Bird, Bristol-Myers Squibb, USA; J.-S. Li, Clinical Research Inst. of Montreal, Canada) has been confirmed. Interestingly, in the rat the non-peptide antagonist SB 209670 also reduces neointima formation after endothelin injury by balloon angioplasty (E. Ohlstein, SmithKline Beecham, USA). This once again draws our attention to the fact that we must consider endothelins not only as spasmogens in cardiovascular disease. They may well also be involved in other pathological vascular changes, such as the hyperplasia that occurs in hypertension and atherosclerosis.
The further development for which many researchers are still impatient is the production of non-peptide antagonists that are highly selective for the $\mathrm{ET}_{\mathrm{A}}$ or $\mathrm{ET}_{\mathrm{B}}$ receptor, together with inhibitors of the action of ECE. These would permit the fine delineation of the different roles these elements have in changes driven by the endothelin system. Such newer receptor antagonists may also help us finally to decide how many functional endothelin receptors there are. So far, only two genes for endothelin receptors have been identified in mammals, encoding the $\mathrm{ET}_{\mathrm{A}}$ and $\mathrm{ET}_{\mathrm{B}}$ receptor, respectively. However, assorted pharmacological evidence, including discrepancies between the rank order of affinity of antagonists to receptors and the effects of specific antagonists, speak to the pharmacologist of subclasses of endothelin receptors.

For the intracellular signalling events following endothelin receptor stimulation, it seems broadly that phosphatidylinositol hydrolysis and calcium mobilization are crucial in many short-term responses to the endothelins, such as contraction and secretion. Activation of mitogen-activated protein kinase, however, seems to be important for long-term events like cell division and hypertrophy (M. J. Dunn, Case Western Reserve Univ., USA).

What of the future? The continuing observations that endothelins are expressed in non-vascular tissues, such as the gastrointestinal and respiratory tracts, renal tissue, neural and glial cells (Y. Tomobe, Tsukuba Univ.; S. Uhlig, Univ. of Konstanz; F. E. Karet, Univ. of Cambridge; S. M. Cazaubon, ICGM, France) and that important crosstalk exists between the endothelins, cytokines (P. Klemm, William Harvey Research Inst. UK) and other vasoactive agents, all indicate areas that need to be further investigated. We are also less certain about the actions of endogenously produced ET-2 and ET-3 than we are of endogenously produced ET-1. Nonetheless, by using selective endothelin receptor antagonists, ECE inhibitors, and animals deficient in portions of the endothelin system, the physiological and pathological roles of all of the endothelins should eventually be revealed.

Katsutoshi Goto is in the Department of Pharmacology, Institute of Basic Medical Sciences, The University of Tsukuba, Tsukuba, Ibariki 305, Japan. Timothy D. Warner is at The William Harvey Research Institute, The Medical College of St Bartholomew's Hospital, London EC1M 6BQ, UK.

\footnotetext{
1. Rubanyi, G. M. \& Polokoff, M. A. Pharmac. Rev. 46 325-415 (1994)

. Kurihara, Y. etal. Nature 368, 703-710 (1994)

3. Baynash, A. G. et al. Cell 79, 1277-1285 (1994).

4. Xu, D. etal. Cell 78.473-485 (1994).

5. Miyauchi, T. etal. Circ. Res. 73, 887-897 (1993).
}

\section{Internal resistance}

A CERTAIN bold space suit design has never been seriously developed. The conventional space suit fits loosely, and is pressurized with air. Imagine it being tightened until the pressure on the skin is exerted not by entrapped air, but by the fabric itself. Air pressure is then not needed. A fabric strong and inextensible enough to contain the pressure of the body would not even need to be gas-tight. A figure-hugging open weave would do. Between its restraining meshes, the skin would be directly exposed to space. It could sweat freely into $0 \%$ humidity, keeping the astronaut cool. He could walk through space in little more than an air-fed helmet and a body-stocking.

Daedalus has an earthly application for this idea: diagnostic electrical resistance tomography. By measuring the resistance between each point on the body's surface and every other point, it is possible to compute a resistance-map of its interior. The principle has been used to study the chest (the air-filled lungs are perfect insulators, and give a clear outline), and can clearly be taken further. Daedalus will fit the patient with a space body-stocking and immerse him, not in high vacuum, but in low-pressure neon. He can then serve as an electrode for a neon discharge display.

Current will enter the patient via a springy, mobile electrode. It will leave by a distributed glow discharge over his whole body, whose intensity at each point will indicate the local potential. High frequency a.c. will be used, which is not painful. The gas pressure and current density will be chosen to confine the neon glow to the patient's surface (as in those neon 'candles' whose discharges wander over their electrode surfaces). As the entry-electrode travels over his body surface, possibly in a helical scan, a TV system will digitize his changing pattern of personal illumination, and feed it into the system computer. In due course a three-dimensional whole-body resistance map should emerge.

Resistance tomography will reveal the body's interior in a novel neon light. Bones will show up as insulators, while nerves and blood-vessels will appear as conducting channels. Fractures, perforations and other injuries will shine out in high relief by the conductive paths they form through the damaged tissues. Furthermore, high-frequency currents can have a useful healing effect. Once the resistance-map has been computed, it will show where to attach electrodes later, so as to send such a current selectively along an internal damagetrack, and encourage its rapid healing.

David Jones 